\title{
Prostatic artery embolization for giant prostatic hyperplasia: a single-center experience
}

\author{
Embolização das artérias prostáticas para o tratamento da hiperplasia prostática gigante: experiência \\ de um único centro
}

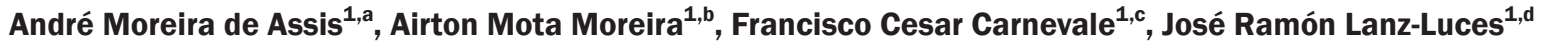

1. Interventional Radiology Department, Instituto de Radiologia do Hospital das Clínicas da Faculdade de Medicina da Universidade de São Paulo (InRad/HC-FMUSP), São Paulo, SP, Brazil.

Correspondence: Dr. André Moreira de Assis. Departamento de Radiologia Intervencionista - InRad/HC-FMUSP. Avenida Doutor Enéas Carvalho de Aguiar, 255, Cerqueira César. São Paulo, SP, Brazil, 05403-000. Email: andre.massis@hc.fm.usp.br.

a. https://orcid.org/0000-0001-8924-7680; b. https://orcid.org/0000-0002-0649-2208; c. https://orcid.org/0000-0003-2659-9624;

d. https://orcid.org/0000-0003-2252-2435.

Received 2 July 2020. Accepted after revision 12 August 2020.

How to cite this article:

Assis AM, Moreira AM, Carnevale FC, Lanz-Luces JR. Prostatic artery embolization for giant prostatic hyperplasia: a single-center experience. Radiol Bras. 2021 Jul/Ago;54(4):219-224.

Abstract Objective: To describe the safety and efficacy of prostatic artery embolization (PAE) in patients with a markedly enlarged prostate. Materials and Methods: This was a retrospective study including 18 consecutive patients (mean age, 74 years) with benign prostatic hyperplasia, all with a prostate volume $\geq 200 \mathrm{~cm}^{3}$, who were enrolled to receive PAE for the treatment of moderate-to-severe lower urinary tract symptoms.

Results: The PAE procedure was technically successful in 17 patients (94.4\%). During follow-up, clinical failure (defined as an International Prostate Symptom Score [IPSS] $\geq 8$ ) was observed in two (11.1\%) of those 18 patients. At 3 months of follow-up, there was significant improvement over baseline in all relevant outcome measures: total IPSS (from 15.7 to 2.9); IPSS quality of life score (from 5.2 to 1.0); prostate specific antigen (from 11.4 to $1.82 \mathrm{ng} / \mathrm{mL}$ ); peak urinary flow rate (from 7.45 to $18.6 \mathrm{~mL} / \mathrm{s}$ ); prostate volume (from 252.4 to $151.6 \mathrm{~cm}^{3}$ ); and post-void residual volume (from 143.7 to $28.3 \mathrm{~mL}$ ) $-p<0.05$ for all. Of the 18 patients, one (5.6\%) presented detachment of prostate tissue and self-limited hematuria, which did not require specific treatment.

Conclusion: In patients with a markedly enlarged prostate, PAE proved to be safe and effective, resulting in significant improvements in clinical, imaging, and urodynamic parameters.

Keywords: Prostate/blood supply; Embolization, therapeutic; Prostatic hyperplasia/diagnostic imaging; Lower urinary tract symptoms; Severity of illness index; Quality of life.

Resumo Objetivo: Descrever a segurança e eficácia da embolização das artérias prostáticas (EAP) em pacientes com próstatas muito aumentadas $\left(\geq 200 \mathrm{~cm}^{3}\right)$.

Materiais e Métodos: Este estudo retrospectivo incluiu 18 pacientes consecutivos com hiperplasia prostática benigna portadores de próstatas $\geq 200 \mathrm{~cm}^{3}$ (idade média de 74 anos), que foram submetidos a EAP para tratar sintomas de trato urinário inferior moderados a graves.

Resultados: A EAP foi tecnicamente bem-sucedida em 17 pacientes $(94,4 \%)$. Falha clínica (IPSS $\geq 8$ ) foi detectada em dois pacientes durante o seguimento (11,1\%). Observamos melhora significativa em todos os parâmetros relevantes aos três meses de acompanhamento: IPSS: 15,7 vs. 2,9; qualidade de vida: 5,2 vs. 1,0); PSA: 11,4 vs. 1,82 ng/mL; pico de fluxo urinário: 7,45 vs. $18,6 \mathrm{~mL} / \mathrm{s}$ ); volume prostático: 252,4 vs. $151,6 \mathrm{~cm}^{3}$; e volume urinário residual: 143,7 vs. $28,3 \mathrm{~mL}-p<0,05$ para todos). Um paciente $(5,6 \%)$ apresentou eliminação de tecido prostático e hematúria autolimitada durante o seguimento, que não necessitou de tratamento específico.

Conclusão: A EAP em pacientes com próstata muito aumentada foi segura e eficaz, com significativas melhoras clínica, urodinâmica e imaginológica.

Unitermos: Próstata/irrigação sanguínea; Embolização terapêutica; Hiperplasia prostática/diagnóstico por imagem; Sintomas do trato urinário inferior; Î́ndice de gravidade de doença; Qualidade de vida.

\section{INTRODUCTION}

As the average age of the population continues to rise, mainly because of better living conditions-including improved health care, healthier nutrition, and early disease detection-physicians are facing aging-related conditions, including benign prostatic hyperplasia (BPH), with everincreasing frequency. An enlarged prostate is common in men over 50 years of age and may or may not be accompanied by deleterious lower urinary tract symptoms (LUTS). In the absence of clinical signs, BPH can go undetected 
for quite some time, and the volume of the prostate can therefore increase significantly before appropriate treatment is given. In addition to age, risk factors for $\mathrm{BPH}$ include obesity, a condition that is prevalent worldwide, which is linked to metabolic syndrome and hormone imbalance, including changes in the ratio between circulating androgens and circulating estrogens ${ }^{(1,2)}$. Consequently, the aromatase enzyme that mediates the production of estrogens from testosterone ${ }^{(3)}$ could explain why testosterone levels in men drop by about $35 \%$ between the ages of 21 and 85, while estradiol levels either remain constant or increase. In rare cases, BPH can lead to a pronounced increase in prostate volume, resulting in a condition known as giant prostatic hyperplasia ${ }^{(4,5)}$.

Although surgical techniques such as holmium laser enucleation of the prostate and simple (open, robotic, or laparoscopic) prostatectomy have gained ground in dealing with severe prostate enlargement, they are associated with relevant morbidity, including retrograde ejaculation, intraoperative bleeding, urinary incontinence, and erectile dysfunction ${ }^{(6)}$, making it desirable to investigate minimally-invasive, low-morbidity alternative procedures. The objective of this study was to explore the clinical benefits, efficacy, and safety of prostatic artery embolization (PAE) in patients with a markedly enlarged prostate due to $\mathrm{BPH}$.

\section{MATERIALS AND METHODS}

This was a retrospective study of 18 consecutive patients with $\mathrm{BPH}$ and a prostate volume $\geq 200 \mathrm{~cm}^{3}$, enrolled to receive PAE between March 2013 and May 2019 (Figure 1). Urologists referred all patients after considering PAE as an option for the treatment of LUTS. All participating patients gave written informed consent.

The medical staff assessed symptom severity and quality of life (QoL) by calculating the total International Prostate Symptom Score (IPSS) and the score on the IPSS QoL item, respectively ${ }^{(7)}$. The inclusion criteria were as follows: being $\geq 40$ years of age; having a prostate volume $\geq 200 \mathrm{~cm}^{3}$; having been diagnosed with $\mathrm{BPH}$; and presenting with $\mathrm{a} \geq 6$-month history of moderate-to-severe symptoms that were refractory to medical treatment, defined as an IPSS $\geq 8$, or treatment-refractory acute urinary retention. Patients with histologically confirmed malignancy were excluded, as were those with large bladder diverticula, those with large bladder stones, those with chronic kidney disease, those with active urinary tract infection, and those with dysregulated coagulation.

The outcome measures, which were determined at baseline and at 3 months after PAE, were as follows: the total IPSS; the IPSS QoL item score; the prostate specific antigen (PSA) level; the peak urinary flow rate; prostate volume; and post-void residual volume (PVR), as determined by ultrasound. All patients also underwent magnetic resonance imaging (MRI) before PAE. The baseline characteristics of the patients are shown in Table 1.

Technical success of the PAE was defined as bilateral embolization. Clinical failure was defined as an IPSS $\geq$ 8 or an IPSS QoL item score $\geq 3$ at 3 months after the procedure, or inability to remove the indwelling catheter in patients with urinary retention. Complications were categorized in accordance with a modified version of the Clavien classification system for interventional radiology embolization procedures ${ }^{(8)}$.

Table 1-Baseline characteristics of patients with BPH.

\begin{tabular}{lcc}
\hline Characteristic & Mean \pm SD & Range \\
\hline Age (years) & $73.4 \pm 9.0$ & $60-92$ \\
IPSS & $15.73 \pm 4.2$ & $9-22$ \\
IPSS QoL item score & $5.16 \pm 1.1$ & $3-6$ \\
PSA (ng/mL) & $11.97 \pm 9.0$ & $0.87-31$ \\
Peak urinary flow rate $(\mathrm{mL} / \mathrm{s})$ & $7.49 \pm 4.1$ & $2-18$ \\
Prostate volume $\left(\mathrm{cm}^{3}\right)$ & $252.35 \pm 44.9$ & $202-348$ \\
PVR $(\mathrm{mL})$ & $143.72 \pm 159.4$ & $7-600$ \\
\hline
\end{tabular}

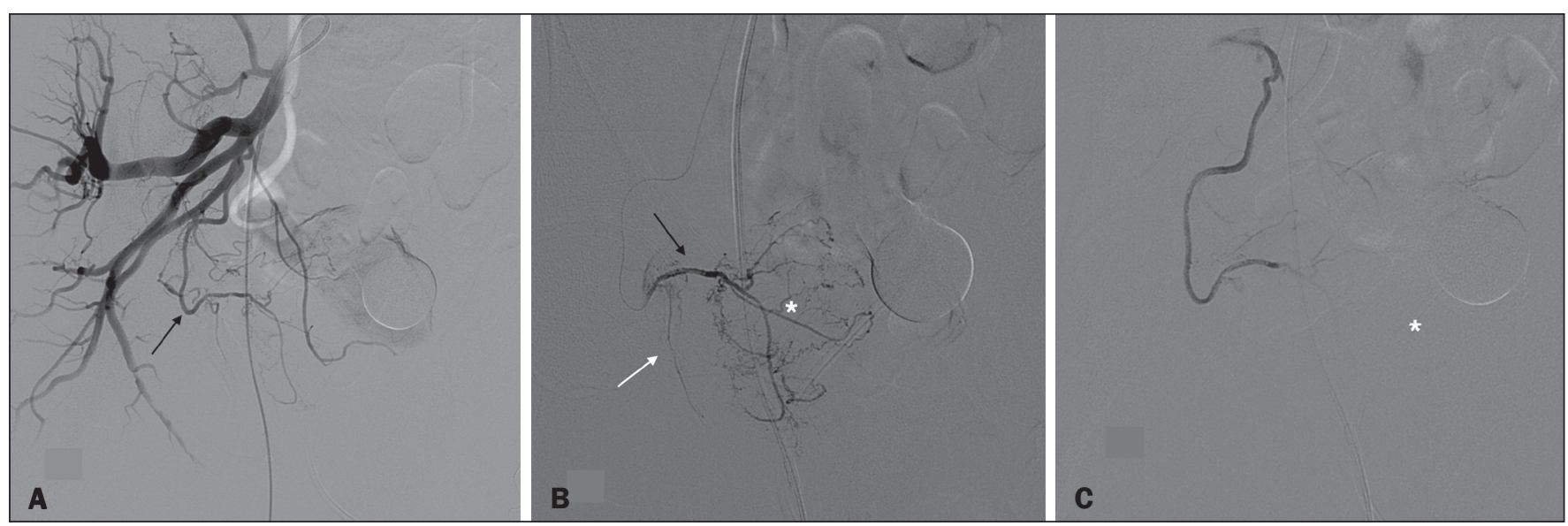

Figure 1. A: Digital subtraction angiography showing the right prostatic artery (arrow) originating from a common trunk with the superior vesical artery (type origin). B: Superselective digital subtraction angiography of the right prostatic artery, showing the anteromedial branch (black arrow), the posterolateral branch (white arrow), and the hypervascularized right transitional zone (asterisk). C: Superselective digital subtraction angiography, performed after embolization, showing devascularization with no residual blush. 


\section{Imaging}

Before and after PAE, MRI of the prostate was performed in either a 1.5-T scanner or a 3.0-T scanner, with a pelvic phased-array coil (Figure 2). An endorectal coil was not used. Gadolinium-based contrast medium was administered with a power injector at a dose of $0.1 \mathrm{~mL} / \mathrm{kg}$ or 0.2 $\mathrm{mL} / \mathrm{kg}$, followed by a $20-\mathrm{mL}$ saline flush. Prostate volume was calculated by the prolate ellipsoid formula:

Prostate volume $=$ length $\times$ height $\times$ width $\times(\pi / 6)$

Two reviewers analyzed each MRI study, and disagreements were resolved by consensus, as recommended in the European Society of Urogenital Radiology guidelines ${ }^{(9)}$.

\section{PAE procedure}

All patients underwent bilateral PAE according to previously described techniques ${ }^{(10-12)}$, the aim being the embolization of every single blood vessel feeding the prostate. All angiographic and PAE procedures were performed in an interventional radiology suite equipped with a catheterization angiography laboratory (Innova 4100; GE Healthcare, Milwaukee, WI, USA) and an augmented fluoroscopy system (Vessel ASSIST; GE Healthcare), with administration of the nonionic contrast medium iodixanol $(320 \mathrm{mg} / \mathrm{mL}$, Visipaque; GE Healthcare Ireland Limited, Cork, Ireland).

All procedures were performed under local anesthesia with a unilateral femoral approach, and the prostatic arteries
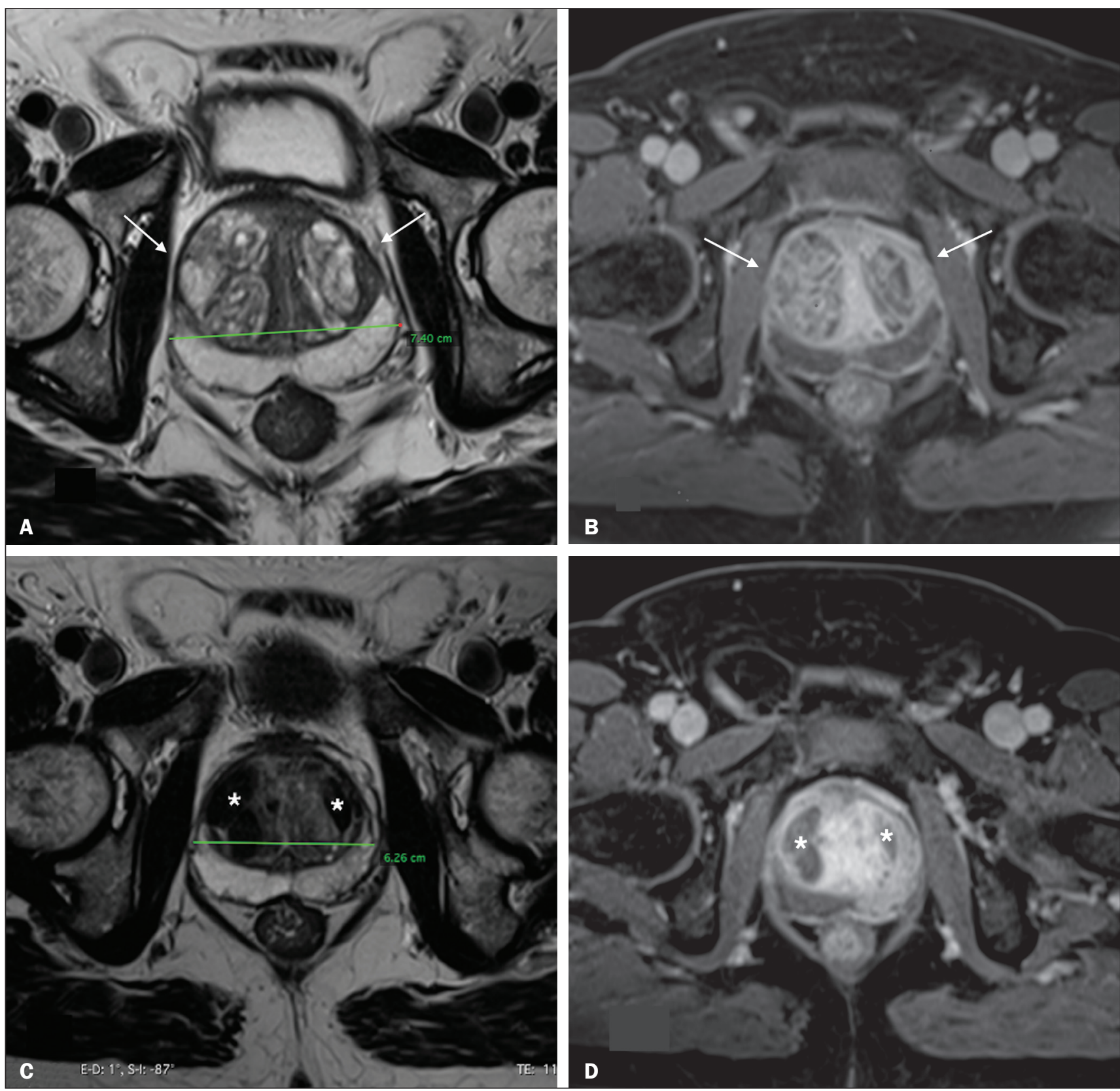

Figure 2. T2-weighted MRI sequence and contrast-enhanced T1-weighted MRI sequence with fat suppression (A and B, respectively), showing a markedly enlarged prostate due to bilateral BPH nodules in the transitional zone (arrows). C,D: T2-weighted MRI sequence and contrast-enhanced T1-weighted MRI sequence with fat suppression, both obtained after PAE (C and D, respectively), showing a reduction in prostate volume and infarction of the BPH nodules bilaterally (asterisks). 
were catheterized with 2.0 Fr microcatheters (Progreat; Terumo, Tokyo, Japan). Each PAE was performed with $300-500 \mu \mathrm{m}$ or with a combination of $100-300 \mu \mathrm{m}$ and 300-500 $\mu \mathrm{m}$ of trisacryl gelatin microspheres (Embosphere Microspheres; Merit Medical Systems, South Jordan, UT, USA). Intraprocedural findings were confirmed by cone-beam computed tomography.

Patients received ciprofloxacin, $400 \mathrm{mg}$ intravenously, in a single dose, before the procedure and $500 \mathrm{mg}$ orally twice a day for one week thereafter. Patients were instructed to use nonsteroidal anti-inflammatory drugs, opioid analgesics, or both, as necessary, after the procedure. To lessen the effects of post-PAE syndrome, alpha blockers were maintained for 1-4 weeks after the procedure. Patients were discharged from the hospital on the same day of PAE and were followed by urologists and interventional radiologists.

\section{Statistical analysis}

Categorical variables are expressed as absolute and relative frequencies, whereas continuous variables are expressed as means and standard deviations. The Wilcoxon signed-rank test was used in order to compare measures between baseline and 3 months of follow-up. Values of $p$ $<0.05$ were considered significant, and all tests were twotailed. Statistical analysis was performed with the SPSS Statistics software package, version 23.0 (IBM Corp., Armonk, NY, USA).

\section{RESULTS}

Between March 2013 and May 2019, 18 patients with giant prostatic hyperplasia underwent PAE. Although the mean follow-up period was $22 \pm 20$ months (range, 3-72 months), the outcomes were analyzed at 3 months, mainly because four patients $(22.2 \%)$ were included more recently. Technical success (bilateral embolization) was achieved in 17 patients (94\%). At 3 months of follow-up, one patient $(5.6 \%)$ had an IPSS $\geq 8$ and the indwelling catheter could not be removed in another patient $(5.6 \%)$. Therefore, the clinical failure rate was $11.1 \%$.

It is noteworthy that, at baseline, the studied population had moderate-to-severe IPSSs (range, 9-22). At 3 months after PAE, the IPSS showed an $81.3 \%$ reduction when compared with the baseline value $(2.9 \pm 2.8$ vs. $15.73 \pm 4.2 ; p=0.001)$. Similar decreases were observed for the IPSS QoL item score, PSA level, and PVR. The peak urinary flow rate showed a mean increase of 11.2 $\mathrm{mL} / \mathrm{s}$, whereas prostate volume showed a mean reduction of $100.8 \mathrm{~cm}^{3}$ ( $p<0.05$ for both). The comparisons between the baseline values and those obtained at 3 months of follow-up are summarized in Table 2. Notably, the 11.2 $\mathrm{mL} / \mathrm{s}$ mean increase in the peak urinary flow rate corresponded to a $149.73 \%$ increase over the baseline value. Also at 3 months of follow-up, one patient presented detachment of prostate tissue, accompanied by self-limited hematuria. No other specific complications were observed.

\section{DISCUSSION}

When seen in men, LUTS have traditionally been associated with BPH. The goal of PAE as an alternative therapeutic approach to address BPH is to relieve LUTS, as well as to slow the progression of the disease while improving QoL. Nonetheless, recent studies have demonstrated that LUTS may be caused by other pathophysiologic processes ${ }^{(13)}$. An increasing body of evidence suggests that inflammation is a common pathophysiological cause of LUTS and metabolic syndrome ${ }^{(14,15)}$. Rapid clinical improvement after PAE is common and may be due to early ischemia of the prostate gland, which reduces its volume and increases its elasticity ${ }^{(16,17)}$. In addition, PAE can prevent the conversion of testosterone to dihydrotestosterone (one of the factors associated with LUTS), with consequent urodynamic improvement due to resolution of the bladder outlet obstruction caused by BPH. It should be borne in mind that a prostate volume $\geq 200 \mathrm{~cm}^{3}$ is not common and that patients with such marked prostate enlargement may have a different natural history of disease than have those evaluated in the majority of previous studies of PAE. Therefore, this specific subgroup of patients merits further investigation.

Holmium laser enucleation of the prostate is a promising alternative for the treatment of giant prostatic hyperplasia, because it provides beneficial results and is associated with lower morbidity than is open prostatectomy. However, it has some relevant drawbacks, include its high cost, the steep learning curve, the need for specialized equipment, the long urethral instrumentation times, and the need to morcellate the laser-resected tissue that migrates into the bladder. Nevertheless, open prostatectomy involves extraperitoneal incision, necessitates blood transfusion, has a risk of neurovascular, sphincter, or rectal

Table 2-Summary of changes in relevant outcome measures.

\begin{tabular}{|c|c|c|c|c|c|}
\hline Outcome measure & $\begin{array}{c}\text { Baseline } \\
\text { Mean } \pm \text { SD }\end{array}$ & $\begin{array}{c}3 \text { months } \\
\text { Mean } \pm \text { SD }\end{array}$ & $P$ & Change & $\begin{array}{c}\Delta \text { change } \\
(\%)\end{array}$ \\
\hline IPSS & $15.7 \pm 4.2$ & $2.9 \pm 2.9$ & 0.001 & -12.8 & -81.3 \\
\hline IPSS QoL item score & $5.2 \pm 1.1$ & $1.0 \pm 0.7$ & 0.005 & -4.2 & -80.6 \\
\hline PSA (ng/mL) & $11.3 \pm 9.0$ & $1.82 \pm 1.6$ & $<0.001$ & -9.6 & -84.0 \\
\hline Peak urinary flow rate $(\mathrm{mL} / \mathrm{s})$ & $7.5 \pm 4.1$ & $18.6 \pm 8.4$ & 0.012 & +11.2 & +149.7 \\
\hline Prostate volume $\left(\mathrm{cm}^{3}\right)$ & $252.4 \pm 45.0$ & $151.6 \pm 36.0$ & 0.001 & -100.8 & -40.0 \\
\hline PVR (mL/s) & $143.7 \pm 159.4$ & $28.3 \pm 14.6$ & 0.028 & -115.4 & -80.3 \\
\hline
\end{tabular}


injury, prolongs the hospital stay, and increases catheterization time ${ }^{(18)}$. The guidelines established by the American Urological Association show a flowchart recommending open prostatectomy for large prostates and other surgical procedures for small and average-sized glands ${ }^{(19)}$. In this specific group of patients (with a prostate volume $\geq$ $200 \mathrm{~cm}^{3}$ ), PAE seems especially appealing because of its favorable profile in terms of complications, with a very low incidence of retrograde ejaculation and no impairment of sexual function. In addition, PAE can be performed as an outpatient procedure, allowing a faster recovery, and does not require bladder catheterization ${ }^{(20)}$.

In general, the results obtained in the present study are similar to those reported in previous studies of PAE, including one involving patients with a prostate volume $>80 \mathrm{~cm}^{3}$ and a mean baseline prostate volume of 129.4 $\mathrm{cm}^{3(21)}$. Another study described the use of PAE in treating patients with a prostate volume $>90 \mathrm{~cm}^{3}$, and the results were similar to those observed in our sample, the authors reporting a $32 \%$ reduction in prostate volume and an $85.2 \%$ decrease in the IPSS, also at 3 months of followup $^{(22)}$. Hwang et al. ${ }^{(23)}$, comparing embolization particle types in a population with a mean age of 78 years, similar to that of our study population, reported a mean prostate volume of $89.4 \pm 59.3 \mathrm{~cm}^{3}$, with a maximum of $213.1 \mathrm{~cm}^{3}$, and a significant $(40.24 \%)$ reduction in the IPSS after the procedure (from $24.6 \pm 9.7$ to $14.7 \pm 9.4$ ), although the mean baseline IPSS was higher among their patients than among ours.

In one recent study ${ }^{(24)}$, the use of PAE was shown to be efficacious and safe in a small cohort of patients with giant prostatic hyperplasia (prostate volume $\geq 200 \mathrm{~cm}^{3}$ ), with a mean follow-up period of $5.0 \pm 2.6$ months. In that study, four $(50 \%)$ of the eight patients evaluated had an indwelling urinary catheter and urinary retention at the time of PAE, and it was possible to remove the catheter after the procedure in three of those patients. The authors also reported that, over the course of the follow-up period, there were mean reductions of 16.7 points in the total IPSS and of 3.0 points in the IPSS QoL item score, together with a mean reduction in prostate volume of $32.5 \%$, similar to the improvements seen in the present study. Unfortunately, the peak urinary flow rate was not reported in that study. The mean increase in the peak urinary flow rate observed in our patient sample, as it would be a useful comparative parameter to what was seen in the present investigation (11.2 $\mathrm{mL} / \mathrm{s} ; 149.73 \%$ ) is superior to the $5.51 \mathrm{~mL} / \mathrm{s}$ reported in a previous study of patients undergoing $\mathrm{PAE}^{(20)}$, being comparable to that achieved with classical surgical treatments. There is a need for further studies, involving larger cohorts, in order to confirm this particular finding.

Despite the fact that the mean prostate volume was greater in our patient sample than in those evaluated in previous studies ${ }^{(25)}$, there were no complications requiring specific therapy. This is in line with the complication profile described by Mathevosian et al. ${ }^{(24)}$, although other authors ${ }^{(22)}$ reported one major complication (persistent urinary tract infection requiring hospitalization) in a cohort of patients with a prostate volume $>90 \mathrm{~g}$. In the present study, only one complication was observed, and that complication was a minor one-a case of prostate tissue detachment accompanied by mild LUTS and transient, self-limited hematuria. Other authors have reported cases of tissue elimination, rarely requiring specific treatment, after PAE ${ }^{(26)}$.

Our study has some limitations, primarily the biases inherent to the retrospective, single-center design. The short follow-up period can also be considered a limitation. Studies including larger cohorts and longer follow-up period are warranted in order to corroborate our findings.

\section{CONCLUSION}

In patients with markedly enlarged prostates, PAE is safe and effective, providing significant clinical, imaging, and urodynamic improvements, at least in the short term.

\section{REFERENCES}

1. Engin A. The definition and prevalence of obesity and metabolic syndrome. Adv Exp Med Biol. 2017;960:1-17.

2. Chavalmane AK, Comeglio P, Morelli A, et al. Sex steroid receptors in male human bladder: expression and biological function. J Sex Med. 2010;7:2698-713.

3. Ellem SJ, Risbridger GP. Aromatase and regulating the estrogen: androgen ratio in the prostate gland. J Steroid Biochem Mol Biol. 2010;118:246-51.

4. Wroclawski ML, Carneiro A, Tristão RA, et al. Giant prostatic hyperplasia: report of a previously asymptomatic man presenting with gross hematuria and hypovolemic shock. Einstein (Sao Paulo). 2015;13:420-2.

5. Wang L, Davis P, McMillan K. A case of giant prostatic hyperplasia. Asian J Urol. 2016;3:53-5.

6. Elzayat EA, Elhilali MM. Holmium laser enucleation of the prostate (HoLEP): the endourologic alternative to open prostatectomy. Eur Urol. 2006;49:87-91.

7. Nickel JC, Saad F. The American Urological Association 2003 guideline on management of benign prostatic hyperplasia: a Canadian opinion. Can J Urol. 2004; 11:2186-93.

8. Moreira AM, de Assis AM, Carnevale FC, et al. A review of adverse events related to prostatic artery embolization for treatment of bladder outlet obstruction due to BPH. Cardiovasc Intervent Radiol. 2017;40:1490-500.

9. Barentsz JO, Richenberg J, Clements R, et al. ESUR prostate MR guidelines 2012. Eur Radiol. 2012;22:746-57.

10. Carnevale FC, Moreira AM, Antunes AA. The "PErFecTED technique": proximal embolization first, then embolize distal for benign prostatic hyperplasia. Cardiovasc Intervent Radiol. 2014;37:16025.

11. de Assis AM, Moreira AM, de Paula Rodrigues VC, et al. Pelvic arterial anatomy relevant to prostatic artery embolisation and proposal for angiographic classification. Cardiovasc Intervent Radiol. 2015;38:855-61.

12. de Assis AM, Moreira AM, Carnevale FC. Angiographic findings during repeat prostatic artery embolization. J Vasc Interv Radiol. 2019;30:645-51.

13. Chapple CR, Wein AJ, Abrams P, et al. Lower urinary tract symptoms revisited: a broader clinical perspective. Eur Urol. 2008;54:563-9. 
14. Ficarra V, Rossanese M, Zazzara M, et al. The role of inflammation in lower urinary tract symptoms (LUTS) due to benign prostatic hyperplasia $(\mathrm{BPH})$ and its potential impact on medical therapy. Curr Urol Rep. 2014;15:463.

15. He Q, Wang Z, Liu G, et al. Metabolic syndrome, inflammation and lower urinary tract symptoms: possible translational links. Prostate Cancer Prostatic Dis. 2016;19:7-13.

16. de Assis AM, Moreira AM, Carnevale FC, et al. Effects of prostatic artery embolization on the dynamic component of benign prostate hyperplasia as assessed by ultrasound elastography: a pilot series. Cardiovasc Intervent Radiol. 2019;42:1001-7.

17. Gao Y, Huang Y, Zhang R, et al. Benign prostatic hyperplasia: prostatic arterial embolization versus transurethral resection of the prostate-a prospective, randomized, and controlled clinical trial. Radiology. 2014;270:920-8.

18. Ferretti M, Phillips J. Prostatectomy for benign prostate disease: open, laparoscopic and robotic techniques. Can J Urol. 2015;22 Suppl 1:60-6.

19. Foster HE, Dahm P, Kohler TS, et al. Surgical management of lower urinary tract symptoms attributed to benign prostatic hyperplasia: AUA Guideline Amendment 2019. J Urol. 2019;202:592-8.

20. Uflacker A, Haskal ZJ, Bilhim T, et al. Meta-analysis of prostatic artery embolization for benign prostatic hyperplasia. J Vasc Interv Radiol. 2016;27:1686-97.

21. Kurbatov D, Russo GI, Lepetukhin A, et al. Prostatic artery embolization for prostate volume greater than $80 \mathrm{~cm} 3$ : results from a single-center prospective study. Urology. 2014;84:400-4.

22. de Assis AM, Moreira AM, de Paula Rodrigues VC, et al. Prostatic artery embolization for treatment of benign prostatic hyperplasia in patients with prostates $>90 \mathrm{~g}$ : a prospective single-center study. J Vasc Interv Radiol. 2015;26:87-93.

23. Hwang JH, Park SW, Chang IS, et al. Comparison of nonspherical polyvinyl alcohol particles and microspheres for prostatic arterial embolization in patients with benign prostatic hyperplasia. Biomed Res Int. 2017;2017:8732351.

24. Mathevosian S, Plotnik AN, McWilliams JP. Prostate artery embolization for giant prostatic enlargement: short-term efficacy and safety. J Vasc Interv Radiol. 2019;30:1820-3.

25. Malling B, Røder MA, Brasso K, et al. Prostate artery embolisation for benign prostatic hyperplasia: a systematic review and metaanalysis. Eur Radiol. 2019;29:287-98.

26. Leite LC, de Assis AM, Moreira AM, et al. Prostatic tissue elimination after prostatic artery embolization (PAE): a report of three cases. Cardiovasc Intervent Radiol. 2017;40:937-41. 